\title{
Metodologia de desenvolvimento eco-sistêmico aplicado ao paradigma do saneamento descentralizado
}

\author{
Eco-systemic Development Methodology applied to the paradigm of decentralized sanitation
}

\author{
Francisco J. P. y L. Madrid', Isabel C. S. Figueiredo², André M. de A. Ferrão ${ }^{3}$, Adriano L. Tonetti ${ }^{4}$ \\ ' Mestrando, Departamento de Saneamento e Ambiente da Faculdade de Engenharia Civil, Arquitetura e Urbanismo - DSA / FEC, UNICAMP, \\ Campinas, SP, Brasil \\ ${ }^{2}$ Doutoranda, Departamento de Saneamento e Ambiente da Faculdade de Engenharia Civil, Arquitetura e Urbanismo - DSA / FEC, UNICAMP, \\ Campinas, SP, Brasil \\ ${ }^{3}$ Professor Livre Docente, Departamento de Recursos Hídricos da Faculdade de Engenharia Civil, Arquitetura e Urbanismo - DRH / FEC, UNI- \\ CAMP, Campinas, SP, Brasil \\ ${ }^{3}$ Professor Doutor, Departamento de Saneamento e Ambiente da Faculdade de Engenharia Civil, Arquitetura e Urbanismo - DSA / FEC, UNI- \\ CAMP, Campinas, SP, Brasil
}

\begin{abstract}
Resumo
As boas práticas de saneamento são ações fundamentais de prevenção de doenças, promoção da saúde, bem estar humano e proteção do meio ambiente. Contudo, a utilização do saneamento como instrumento de promoção de qualidade de vida pressupõe a superação de entraves tecnológicos, políticos e gerenciais que dificultam a extensão desses benefícios às populações que habitam áreas rurais e municípios e localidades de pequeno porte. O presente artigo expõe a complexidade envolvida no alcance do saneamento básico a essas pequenas comunidades e aporta algumas ideias de como é possível encarar a problemática a partir da Metodologia de Desenvolvimento Eco-sistêmico, calcado no Pensamento Complexo de Edgar Morin e Pensamento Eco-Sistêmico elaborado por M.C. Moraes. Para tanto, apresenta-se também a proposta formulada por pesquisadores da UNICAMP para a aplicação da educação ambiental como ferramenta para o engajamento social na busca de melhoria do saneamento em comunidade rural no município de Campinas (SP).
\end{abstract}

Palavras-chaves: Saneamento Descentralizado. Pensamento Complexo. Pensamento Eco-Sistêmico. Educação Ambiental.

\begin{abstract}
Good sanitation practices are fundamental actions for disease prevention, health promotion, human welfare and environmental protection. However, the use of sanitation as a life quality promotional tool requires overcoming of technological, political and managerial obstacles that hinder the extension of these benefits to people living in rural areas and small towns. This article presents the complexity involved in achieving sanitation to these small communities and brings some ideas of how you can face the problem with the Eco-systemic Development Methodology, based on Complex Thought of Edgar Morin and Eco-Systems Thought prepared by M.C. Moraes. Therefore, it is also presented a project prepared by researchers from UNICAMP that aims the application of environmental education as a tool for social engagement in the search for sanitation improvement in a rural community in Campinas City, Sao Paulo state, Brazil.
\end{abstract}

Keywords: Decentralized Sanitation. Complex Thought. Eco-Systemic Thought. Environmental Education. 


\section{INTRODUÇÃO}

A Metodologia de Desenvolvimento Eco-sistêmico proposta por Moraes e De La Torre (2006), calcada no Pensamento Complexo de Edgar Morin e Pensamento Eco-Sistêmico elaborado por M.C. Moraes é compreendida como um processo de construção do conhecimento, retomando, de uma maneira interativa e recursiva, objetivos, estratégias e avaliações feitas em diversos momentos, objetivando uma compreensão mais ampla dos fenômenos envolvidos em uma constante dinâmica de mudanças ocorridas.

O pensamento complexo abrange o entrelaçar de ideias e concepções muitas vezes tidas como antagônicas que se complementam, como a percepção do todo e dos fragmentos, a racionalidade e o lúdico, espírito e matéria, o conhecido e o desconhecido, a certeza e a ilusão, ciência e misticismo, ordem e desordem, o previsível e o imprevisível, dentre outras (MORIN, 2011). O desenvolvimento dessas ideias propicia uma importante aproximação da realidade, dependente de ciclos de análises e interpretações, tendo seu foco tanto de maneira generalista do todo quanto do desmembramento em sistemas mais simplificados, levando-se em conta, principalmente, suas interações e as manifestações de diversos fenômenos em seu contexto, desvendando os campos do conhecimento e do reconhecimento das incertezas. Trata-se de uma postura que adota concomitantemente os modelos linear e sistêmico de raciocínio na formação de uma percepção da realidade (MARIOTTI, 2000).

Direcionado para a pesquisa em Educação, o pensamento eco-sistêmico aporta o entendimento do fluxo existente nas relações de dependência e independência entre os indivíduos e os elementos de ordem cognitiva que permitem a organização e o desenvolvimento da autonomia da pessoa envolvida para com o meio, em interações mútuas, simultâneas e recorrentes (MORAES; DE LA TORRE, 2006).

É possível, portanto, a construção do entendimento da complexidade envolvida no saneamento básico descentralizado no Brasil a partir da Metodologia de Desenvolvimento Eco-sistêmico, buscandose a retomada da situação do saneamento no país, os agentes envolvidos, estratégias empregadas, os cenários formados e possíveis ações de melhoria.

No presente artigo, apresenta-se a proposta formulada por pesquisadores da UNICAMP para a aplicação da educação ambiental como ferramenta para o engajamento social na busca de melhoria do saneamento em comunidade rural no município de Campinas (SP), como tentativa de abordagem holística da temática e formulação de ações para o fortalecimento de laços dos agentes envolvidos.

\section{SISTEMAS DE SANEAMENTO DESCENTRALIZADOS NO BRASIL E EDUCAÇÃO AMBIENTAL / SANITÁRIA}

Segundo a Pesquisa Nacional de Saneamento Básico 2008, pouco mais da metade dos municípios $(55,2 \%)$ possuem algum serviço de esgotamento sanitário por rede coletora (IBGE, 2010). Esse dado torna-se ainda mais alarmante por não vir acompanhado de informações quantitativas e qualitativas sobre os sistemas de tratamento dos esgotos, bem como a porcentagem do esgoto coletado que realmente é tratada no município.

Além disso, o esgoto não coletado tampouco recebe uma disposição adequada, já que em grande parte $(40 \%)$ é destinado a fossas rudimentares, fossas secas, valas a céu aberto, lançamento direto em corpos d'água ou outras alternativas potencialmente impactantes ao ambiente local e à saúde das populações. Essa situação é mais comum em municípios e distritos de menor porte localizados nas áreas rurais (IBGE, 2010). Como muitas vezes não existe definição legal sobre a quem compete a coleta e tratamento do esgoto nas áreas afastadas dos polos urbanos, recai sobre as próprias populações locais a responsabilidade de planejar, construir e operar "soluções" para o tratamento e disposição do seu esgoto.

Embora haja o frequente aporte financeiro federal para implantação de soluções para o saneamento básico em algumas localidades de população isoladas - por intermédio da Fundação Nacional de Saúde (FUNASA-MS) - São tímidas as iniciativas de educação ambiental e sanitária que alavanquem a participação social nas escolhas dos sistemas de tratamento, além de falhas no reconhecimento da realidade particular de cada localidade na elaboração dos projetos das soluções adotadas.

Vale destacar que o pleno conhecimento, envolvimento e participação da população na escolha 
e aplicação de sistemas de tratamento de esgoto e captação de água são fatores essenciais para o seu funcionamento adequado (MASSOUD et al. 2009). Se houver participação popular no processo de escolha do sistema e se ela for envolvida no seu manejo, as chances dele ser efetivo é muito grande. Para os referidos autores, a tecnologia mais apropriada é aquela que é economicamente viável, sustentável ambientalmente e socialmente aceita.

Seria, portanto, imprescindível uma abordagem transdisciplinar para a questão. A transdisciplinaridade, que pressupõe o reconhecimento e interpretação da complexidade de todo um contexto, relacionando e evidenciando seus aspectos culturais, sociais e ambientais envolvidos (D'Ambrosio, 1997), aprimoraria e fortaleceria a visão de que os beneficiários do saneamento básico são os principais indivíduos envolvidos na problemática.

Essa visão holística dos fenômenos envolvidos, ao incorporar a integração e a inter-relação dos agentes, entidades e dos diversos aspectos culturais, sociais e ambientais, torna evidente a necessidade de um fortalecimento das ações de educação ambiental e sanitária, podendo ser considerada como principal ferramenta de estímulo à participação e envolvimento social.

\section{A VISÃO HOLÍSTICA}

As ciências e, consequentemente, a tecnologia atingiram seu atual estágio de desenvolvimento graças a análises e práticas reducionistas cartesianas, fragmentadas em disciplinas, que moldaram uma percepção seletiva de problemas, culminando na diversificada divisão e especialização das áreas do conhecimento (CAPRA, 1982; D’AMBROSIO, 2011).

Em abordagem detalhada dessa evolução científica a partir da visão do mundo cartesiana, Capra (1082) destacou como as diversas metodologias reducionistas geraram enormes avanços na física, biologia e medicina, evidenciando, contudo, a nova necessidade de transformação dessa abordagem, por meio de uma retomada de uma visão sistêmica capaz de remoldar os paradigmas estabelecidos na ciência moderna.

Anteriormente à obra de F. Capra, a Teoria Geral dos Sistemas de Von Bertalanffy (1968), também retomou questionamentos quanto às limitações da abordagem científica reducionista e à fragmentação do conhecimento em diversas áreas comumente isoladas (física, química, biologia, psicologia, etc.), fundamento da concepção de uma visão mais global, sugerindo o reconhecimento de todas as interdependências de um sistema, de modo que a reunião de cada um dos elementos para constituir uma unidade funcional maior, desenvolve qualidades que não se encontram em tais componentes isolados.

Essa concepção de uma visão mais global, uma visão holística, proporciona o enfoque integrado dos elementos envoltos em um determinado contexto, permite justamente o reconhecimento da complexidade da realidade e da transdisciplinaridade dos aspectos sociais, ambientais e culturais envolvidos, postura intrínseca para a compreensão de uma problemática em sua integralidade.

Conforme proposto na Metodologia de Desenvolvimento Eco-sistêmico proposta por Moraes \& De La Torre (2006), calcado no pensamento complexo de Edgar Morin, a análise integrativa e a tomada de conhecimento a partir das partes não dão conta de explicar o funcionamento do todo por meio de um processo linear de resultados assegurados de maneira direta e imediata. Tratando-se de processos que envolvem mudanças estruturais nos mais diversos níveis, o mais conveniente seria recorrer a um procedimento mais dinâmico, interativo, recursivo e não-linear, uma ação em espiral, uma ação que comporta atuação e comprovação em ciclos com a possibilidade de contínua retificação.

Para uma abordagem mais holística da questão dos sistemas de saneamento básico descentralizados, almejando-se uma definição das opções tecnológicas que atendam e satisfaçam as necessidades da população trabalhada, é necessário, antes de qualquer intervenção, o conhecimento das condições técnicas, sociais e culturais da comunidade, para se tomar a decisão definitiva, pois o serviço a ser implantado também deverá satisfazer as aspirações da população a ser beneficiada. Esse conhecimento deve ser buscado nos acervos antropológicos e especialmente na convivência com essas populações, que pode ser transformada em momentos de aprendizagem mútua (ReCESA, 2009).

Cada sociedade possui sua lógica e tecnologias próprias, suas formas de identificar e entender os problemas também próprios, muitas vezes, diferentes das formas de entender dos técnicos envolvidos na formulação de soluções, necessitando, portanto, serem ouvidas, sendo imprescindível o estabeleci- 
mento do diálogo. Para efetivação do mesmo, que nega qualquer forma autoritária e verticalizada na comunicação, é essencial a adoção de uma postura apta a ouvir paciente e criticamente essa população, integrando-a ao diálogo construtivo (FREIRE, 1998). Assim, a melhor solução para um problema não é necessariamente a mais econômica, a mais segura ou a mais moderna, mas, sim, aquela mais apropriada à realidade social, ambiental e cultural em que será empregada.

\section{PROJETO UNICAMP}

Dentro da problemática do saneamento básico em países em desenvolvimento, especialmente em pequenas comunidades ou comunidades isoladas, o (re)conhecimento das peculiaridades da realidade local é fundamental para uma abordagem minuciosa que a complexa questão requer. Segundo Massoud et al. (2009), a formulação de alternativas para o saneamento básico deve abordar ações educativas que visem a melhora da saúde da população, a sua sensibilização e participação para as questões socioambientais envolvidas na questão; o envolvimento das próprias populações locais nesse processo é necessário para garantir sua eficiência e legitimidade.

Nesse contexto, pesquisadores da Faculdade de Engenharia Civil, Arquitetura e Urbanismo da Universidade Estadual de Campinas (FEC-UNICAMP) vêm estudando alternativas de tratamento de esgotos sanitários que sejam tecnicamente e economicamente viáveis para comunidades rurais e/ ou isoladas.

Em complemento à essa linha de pesquisa, desenvolveu-o projeto, proposto por Isabel Campos Salles Figueiredo e Adriano Tonetti, intitulado "Alternativas para o tratamento de esgoto em propriedades rurais de Campinas/SP: Educação, aplicação e difusão de tecnologias sociais", no qual almeja-se a avaliação da situação sanitária de um conjunto de propriedades localizadas na área rural do município de Campinas (SP), na região rural de Pedra Branca. Para tanto, objetiva-se a realização de ações de educação ambiental e sanitária com o envolvimento dos proprietários rurais locais, dos alunos e professores das escolas municipais da região, buscando-se também uma integração desses indivíduos com instituições parceiras para o desenvolvimento, aplicação e difusão de alternativas para o tratamento de esgoto adaptadas à realidade local.

Pretende-se assim, por meio da avaliação da situação sanitária local, estimular o entendimento da população local sobre a melhoria da qualidade de vida proporcionada pelas boas práticas sanitárias, além de despertar nos moradores a busca pelas soluções necessárias para realizar as adequações sanitárias em suas respectivas propriedades, fomentando uma participação ativa dos mesmos tanto no processo de diagnóstico sobre a sua realidade, quanto na tomada de decisão sobre aspectos de saneamento e também na aplicação e manutenção dessas medidas.

Por isso, as famílias envolvidas no diagnóstico serão participantes diretas desse processo, contribuindo para o levantamento de informações acerca da sua realidade local e para a construção da pesquisa onde são atores (DEMO, 2004).

Dentro do eixo das ações de educação ambiental e sanitária, prevê-se a promoção de oficinas práticas e palestras para a comunidade local sobre o tema Tratamento de Esgoto, buscando-se o desenvolvimento de material com fins educativos para a divulgação de boas práticas sanitárias e opções / alternativas de sistemas para o tratamento do esgoto.

Desse modo, entre a população a ser contemplada (cerca de 40 famílias), as ações de educação ambiental objetivam a melhoria das condições sanitárias dessa comunidade, através da sensibilização e informação sobre a questão do saneamento e seus impactos socioambientais, além do apoio técnico e científico para o manejo adequado das águas de abastecimento, esgoto e resíduos sólidos nas propriedades rurais envolvidas.

O projeto conta com a parceria de diversas entidades, buscando estreitar os laços entre os agentes envolvidos e beneficiários, dentre os quais vale destacar: Secretaria do Verde, Meio Ambiente e Desenvolvimento Sustentável do Município de Campinas; Sindicato Rural de Campinas (SRC); Associação de Agricultura Natural de Campinas e Região (ANC); Comitê de Bacia Hidrográfica dos rios Piracicaba, Capivari e Jundiaí (Comitê PCJ) através da Câmara Técnica Uso e Conservação da Água no Meio Rural (CT- Rural); e Associação Brasileira de Engenharia Ambiental e Sanitária (ABES) e sua Câmara Técnica de Saneamento e Saúde em Comunidades Isoladas. 


\section{RESULTADOS ESPERADOS}

A proposta de aplicação da educação ambiental como ferramenta para o engajamento social na busca de melhoria de sistemas de saneamento descentralizado é uma tentativa de ruptura dos entraves tecnológicos, políticos e gerenciais que atualmente dificultam a difusão adequada do saneamento ambiental às populações que habitam áreas rurais e localidades de pequeno porte afastadas dos centros urbanos.

É uma tentativa de integrar os agentes envolvidos no processo, tendo claramente uma meta inicial de difícil alcance: um diagnóstico da situação sanitária da localidade alvo com ampla participação dos moradores locais, buscando-se conhecer a realidade local através do conhecimento das condições técnicas, sociais e culturais da comunidade, integrando-as às condicionantes ambientais (aspectos geomorfológicos e climáticos) e atividades desenvolvidas no local para a seleção de alternativas tecnologica e economicamente viáveis.

Busca-se, portanto, a integração da aplicação do desenvolvimento tecnológico obtido por pesquisa acadêmica com os agentes locais e instituições públicas locais, nos quais os beneficiários diretos são os atores que indicarão as melhores soluções e garantirão a devida manutenção dos sistemas. Como proporcionar então um contínuo apoio técnico que permita a longevidade dessa integração? Como integrar a pesquisa científica com o poder público e população local? Esses são os grandes desafios a serem inicialmente destrinchados na presente proposta.

\section{REFERÊNCIAS}

CAPRA, Fritjof. O ponto de mutação. 9. ed. São Paulo: Cultrix. 1982.

D'AMBROSIO, Ubiratan. A transdisciplinaridade como uma resposta à sustentabilidade. Terceiro Incluído. DOI 10.5216/TERI.V1I1.14393. 2011.

D’AMBROSIO, Ubiratan. Transdisciplinaridade. 2. ed. São Paulo: Palas Athena. 1997.

DEMO, Pedro. Pesquisa participante: saber pensar e intervir juntos. Brasília: Liber Livro Editora. 2004.

FREIRE, Paulo. 1998. A. Pedagogia da autonomia: saberes necessários à prática educativa. São Paulo: Coleção Leitura Paz e Terra.

IBGE 2010. Pesquisa Nacional de Saneamento Básico 2008. Instituto Brasileiro de Geografia e Estatística, Rio de Janeiro.

MARIOTTI, Humberto. As paixões do ego. 3. ed. São Paulo: Palas Athena. 2000.

MORAES, M.C. \& DE LA TORRE, S. Pesquisando a partir do pensamento complexo - elementos para uma metodologia de desenvolvimento eco-sistêmico. Educação. n. 1 (58), p. 145-172. Porto Alegre - RS. 2006.

MASSOUD, M. A.; TARHINI, A.; NASR, J. A. Decentralized approaches to wastewater treatment and management: Applicability in developing countries. Journal of Environmental Management. Vol. 90, p. 652-659. 2009.

MORIN, Edgard. Os sete saberes necessários à educação do futuro. 2. ed. revisada. Brasília: Cortez; UNESCO. 2011.

ReCESA. Transversal: saneamento básico integrado às comunidades rurais e populações Tradicionais: guia do profissional em treinamento : nível 2. Ministério das Cidades. Secretaria Nacional de Saneamento Ambiental (org.). Brasília: Ministério das Cidades. 2009.

VON BERTALANFFY, Ludwig. General System Theory. New York: George Braziller. 1968. 